\title{
Abismos temporales. Feminismo, estéticas travestis y teoria queer
}

Richard, Nelly (2018)

Santiago de Chile, Ediciones Metales Pesados. 225 pp.

\section{- Fernanda Carvajal IIEG-IIGG-CONICET}

¿Puede ser el maquillaje una figura del tiempo? Sabemos del maquillaje como tecnología de género, como artilugio de embellecimiento y disimulo de la mancha y la falla, como oportunidad para la experimentación y mutación de sí, sabemos del maquillaje como arma de un rostro que quiere combatir el paso del tiempo, los deterioros y caídas de la piel. El vínculo entre maquillaje y simulación está a la mano, pero ¿qué sucede cuando se nos aparece esa otra fisonomía del maquillaje, no solo como promesa cosmética, como freno del tiempo, sino como polvo, ${ }^{1}$ como huella de una extinción? La portada de Abismos temporales escoge como imagen la obra de la artista chilena Isidora Bravo, Polvo cuico, una polvera de marca con un motivo porno grabado, como el secreto bien guardado de una "señora bien". El espejo y el dedo que toca para tocarse, el re-tocarse programado por la polvera como pequeño dispositivo escópico, perturba la distribución entre una subjetividad masculina marcada como activa-voyeurista y otra femenina marcada como pasivo-exhibicionista, codificada por la pornografía. La perversidad pornográfica del "se mira pero no se toca" encuentra aquí otra experiencia con la mirada y con el roce. A diferencia del porno en la pantalla o en una fotografía, el dedo que delicadamente toca la imagen en la polvera la desvanece. Literalmente la pulveriza: abre un abismo. La polvera aparece aquí como todo un modelo de la temporalidad de la escritura y de la mirada.

La escritura de Nelly Richard no hace sistema, su letra crea dispositivos estratégicos abiertos sobre su propio abismo. Su escritura toca y retoca barrocamente las prácticas que inscribe como conjuntos no cerrados, no clausurables, no totalmente formalizables. Los textos de este libro suelen funcionar como un juego de espejos que se refractan entre sí, enfocando una misma imagen o figura desde diferentes perspectivas, mostrando lo que el tiempo le hace a las cosas. Por

1 Polvo que puede hacer también alusión a la dimensión narcótica y sexual de sus acepciones. ejemplo: "las contorsiones excéntricas de la loca" en Pedro Lemebel durante la dictadura son codificadas por Richard como un modo de subjetivación que "transgredía el mandato autoritario de regimentación de identidades uniformadas y el ideologismo revolucionario ético y viril de la izquierda tradicional". En la posdictadura Lemebel es reenfocado, a partir de su aparición durante los años noventa, en diferentes programas televisivos, como un "ícono contracultural que el sistema necesita para espectacularizar su coqueteo promiscuo con la diversidad sexual". Y luego, siendo jurado del en el Festival de Video Arte Porno "Dildo Roza" donde el artista Felipe Rivas presentó su obra Ideología (2011), Lemebel aparece como la voz acreditada de quien quiere "salvar la ideología del ideario de Salvador Allende... del contagio porno-queer".

En este libro hay una ética de la mirada que sabe de la fragilidad situada de las tácticas, que no se adhiere posesivamente a ellas y, en cambio, reacciona a su obsolescencia, lo que resulta imprescindible hoy, cuando advertimos que las homo-lesbo-fobias y transfobias blandas que sostienen nuestra normalidad neoliberal pueden pasar en cualquier momento a duras, implacables formas de violencia heterosexista y cisexual.

Hoy, cuando vemos con vertiginosa claridad, que los modos de castigo e inclusión, de control y permisividad sobre las disidencias sexo-genéricas no se distribuyen de un modo lineal-progresivo, que los "logros" sociales y legales de la comunidad lgtbi y feministas siguen siendo puntos de tensión antes que puntos de llegada, decididamente expuestos a la regresión y la reversibilidad, es preciso sostener una mirada audaz y una lucidez ética. Pues hoy los sectores antiderechos buscan instalar un renovado conservadurismo desde lenguajes no necesariamente conservadores, no le temen a la mezcla y fagocitan discursos y procedimientos acuñados por sectores subalternos a los que históricamente han negado. Un ejemplo de ello ha sido la estrategia del Papa Francisco (el primer pontífice del 
sur global, más precisamente, de un continente que ha producido teorías y políticas de descolonización) para resignificar el discurso conservador del Vaticano en materia de género y sexualidad, haciéndolo convivir con un discurso antineoliberal. ${ }^{2}$

Sabemos que ninguna escritura solamente "registra" aquello sobre lo que se pronuncia. La de Richard no solo tiene el sello de una política de inscripción -inscribe en un debate aquello que toca- sino que ha sabido tener un especial gesto dinamizador al interior del campo cultural chileno, y en lo que este libro retoma intensivamente: el campo de los feminismos y las disidencias sexuales, donde la escritura de Nelly Richard ha sido agitadora, de una incisiva destreza para incitar a tomar posición, así como también, para abrir posiciones inesperadas.

En este ámbito del espacio de las disidencias sexogenéricas y los feminismos, la escritura de Richard ha constituido para varixs de nosotrxs, un campo de posibilidad para descentrar "lo queer", como espacio privilegiado de enunciación teórico-política, a la hora de aproximarnos a saberes y modos de vida que hacen fracasar la norma sexo-genérica. En este sentido, no me parece menor la bajada del título de Abismos temporales: feminismos, estéticas travestis y teoría queer. Richard designa ahí tres zonas político-epistemológicas que se van delineando en un permanente, poroso y conflictivo flujo de roces y tráficos pero también, en una avidez de diferenciación. Quisiera volver aquí puntualmente a las epistemologías diferenciales de lo queer (y a la pregunta por sus zonas de contaminación y discordia con las epistemologías diferenciales de lo trans) para abrir una entre muchas posibles entradas de lectura a este libro.

Es interesante que, por un lado, los textos aquí reunidos trazan vínculos no lineales entre episodios de la disidencia sexo-genérica, que tuvieron lugar en Chile durante los últimos cuarenta años, desde las prácticas artísticas de Carlos Leppe y Juan Domingo Dávila, las Yeguas del Apocalipsis, el activismo del programa triángulo abierto de Juan Pablo Sutherland y Víctor Hugo Robles, la escritura simbiótico-perversa de Lucía Egaña y Josefa Errázuriz, o las indisciplinadas intervenciones políticas de los integrantes de la CUDS (Coordinadora Universitaria de la Diversidad Sexual).

2 De modo que hoy, una de las instituciones nodales en el proceso histórico de la colonización toma como vocero a Bergoglio para denunciar la "ideología de género" como una forma de colonización que estaría actuando a través de órganos internacionales que condicionan la ayuda económica para el "desarrollo" de los países pobres, a la aceptación de políticas liberales-occidentales acerca de los derechos reproductivos y sexuales (Bracke y Paternotte, 2018).
Y, al mismo tiempo, la escritura de Richard mantiene una tensión, una sospecha hacia las traducciones de lo queer, por el tono afectivo-triunfalista-voluntarista y los efectos de borramiento de marcas contextuales que habrían adquirido en sus invocaciones locales.

Richard fue una de las primeras voces que en Chile, durante los años setenta, invocó el psicoanálisis lacaniano, el análisis semiológico en torno a la pose, la noción de "subjetividades en proceso" de Julia Kristeva y luego los análisis en torno al deseo de Gilles Deleuze y Félix Guattari para pensar, desde el arte, formas del deseo y de la identidad sexual que no se ajustaban a la heterosexualidad ni al binarismo, en el contexto de la dictadura cívico-militar liderada por Augusto Pinochet, cuando no habían surgido aún movimientos lgtb organizados. Quisiera volver sobre un episodio de comienzos de los años ochenta que para mí contiene algunas claves para situar la emergencia de la escritura de Richard como escritura diferencial. Me refiero a la video-performance La Biblia que Carlos Leppe y Juan Domingo Dávila realizaron junto a Richard en el Instituto Chileno Francés de Cultura en 1982, y que fue leída por otro intelectual clave de ese período, el filósofo Patricio Marchant (2000 [1982]), como la escena inaugural de una puesta en obra del deseo homosexual.

¿En qué consistió la performance? Al centro de la habitación, Dávila escenificaba "en vivo" una cita de La Pietá (la escultura de Miguel Ángel), que invertía los roles masculino y femenino de la pose, de modo tal que Dávila tomaba el lugar de la Madre, mientras Richard, principal interlocutora crítica de ambos artistas, estaba sentada en el suelo y apoyada en el regazo de Dávila, tomando el lugar de un hijo/hija sexualizado/a y ofrecido/a. Leppe ingresó a la sala poco después, vestido con un traje formal, elegantemente viril, con el rostro maquillado y con pestañas postizas, llevando unos papeles en sus manos. Sobre una mesa, en el centro de la sala, había un jarro y un recipiente de loza con agua con la que Leppe se lavó la cara. Luego el mismo Leppe echó a andar un video (realizado por Dávila) donde se veía nuevamente una cita a La Pietá, esta vez, representada como relación homosexual entre dos hombres. Una vez terminado el video, Leppe repartió un escrito que luego leyó en voz alta. En él utilizaba un lenguaje soez invocando todo el repertorio de injurias e insultos con que el habla popular nombra la homosexualidad, como si dijera: no es posible fijar una verdad del deseo homosexual; lo que hay es el habla amenazante y libidinal de la injuria. En ese discurso, Leppe se pronunciaba sobre su posición en el arte chileno en esos primeros años de la dictadura y reclamaba a Dávila por haberse ido de Chile, autoexiliado a Australia. 


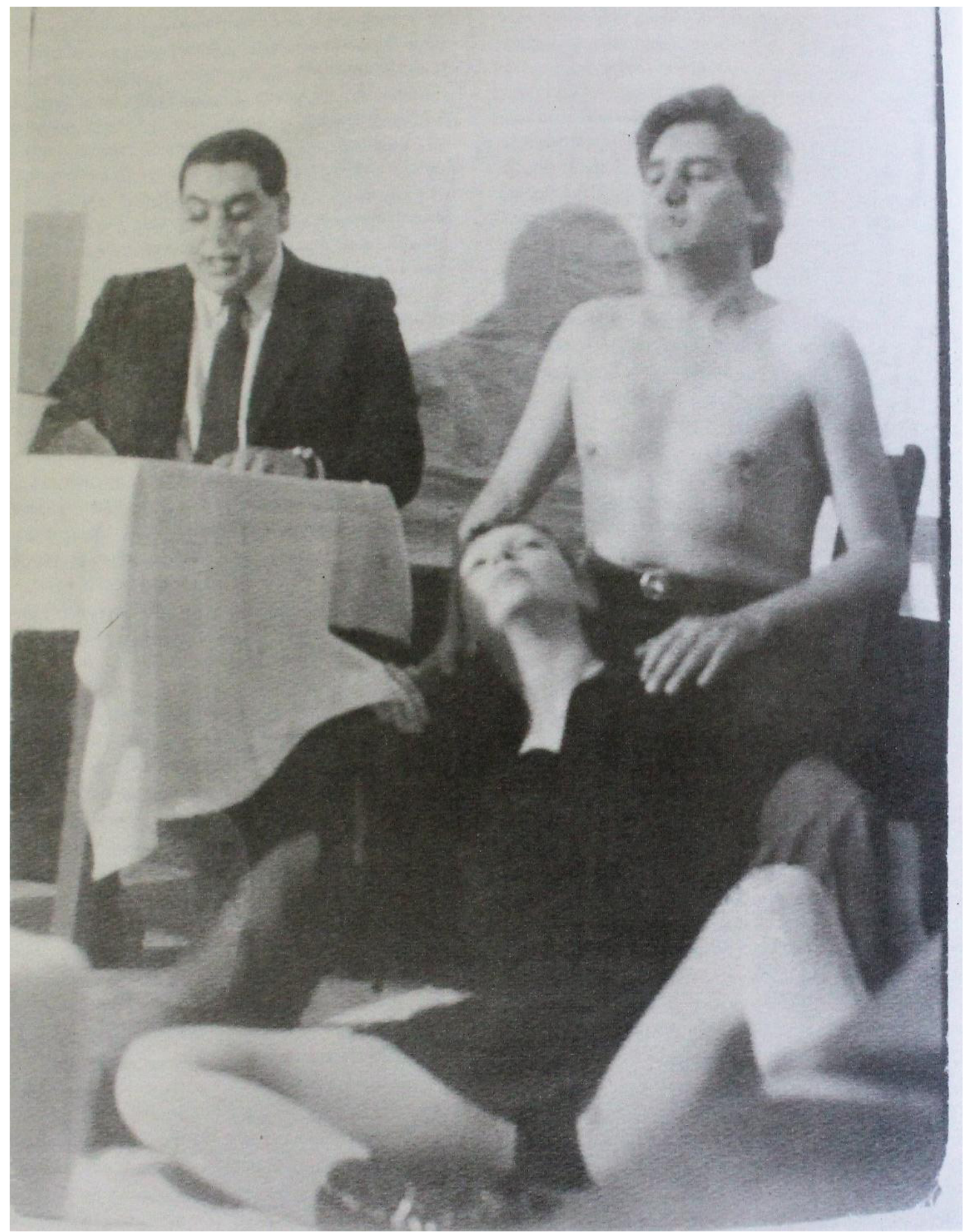

Performance La Biblia. Fotografía Jaime Goycolea

Marchant hace una brillante lectura de esta escena, que no voy a replicar aquí. Pero sí quiero plantear algo que siempre me ha llamado la atención: su silencio sobre la participación que Richard tiene en la acción, convocada a ocupar el lugar del Cristo muerto, recién descendido de la cruz. En una lectura psicoanalítica un tanto reductiva, Justo Pastor Mellado señaló varios años más tarde, que en esta acción Leppe y 
Dávila "hicieron" a Richard "ocupar la posición del falo como objeto caído" (Mellado, 2009: 78). Pero en las imágenes que registran la acción, el cuerpo de Richard no adopta un gesto desfalleciente. Al contrario, el cuerpo de Richard marca el punto de erotización en la imagen, en tanto posa con las piernas abiertas, ofreciéndose. En lugar de la madre teórica o del hijo/a muerto/a, Richard ocupa la posición de una hija/madre sexualizada. Incluso es invocada desde la voz de Leppe como una figura penetrante cuando le dice a Dávila: "Deja que nos meta el texto a más no poder", ubicando la escritura de Richard en un registro libidinal antes que legal (legal en el sentido de quien viene a sancionar la "verdad" sobre la escena). La figura silenciosa e ineludible de la mujer sexuada en el centro de la escena, no solo des-identifica mujer y madre, sino que multiplica los vectores de deseo. Permite pensar que, al parecer en esta ocasión, Marchant no mira para abajo, y que se le escapa que el deseo polimorfo, des-edipizado, que hace ahí su escena, no solo no es heterosexual, sino que podría ser no solo homosexual. Quizá lo que ahí acontecía era la posibilidad espectral de una bisexualidad incitada por las desidentificaciones de género en juego, que ponía en cuestión el propio binomio entre heterosexualidad y homosexualidad.

En esta escena, que tuvo lugar en dictadura (y que podría verse como un pliegue de esa otra escena retomada en el libro, que recuerda la primera presentación de El género en disputa de Judith Butler, realizada por Richard en 1993 en la disco gay Naxus), hay una clave para entender la atracción producida, en distintos momentos de la historia reciente de Chile, entre la escritura de Richard y las prácticas homosexuales, que muestran múltiples modos de parodiar y atentar contra el falocentrismo masculino y a la vez, de producir simbiosis misógino-feministas con lo femenino. Esta escena de alguna manera permite comprender esa atracción entre discurso y prácticas como algo más que una posición de alianza, como algo más que una voz que abrió un espacio de enunciación a una homosexualidad aún sin voz-teórica propia. Alguna vez pensé que lo que ahí estaba trabajando era una función materna y que esa alianza adquiría algo de incestuosa, pero quizá ese modo de codificarlo todavía dejaba muy estable la separación entre palabra y acción. Esta intervención de 1982 perturba la distinción entre esos dos territorios, porque aquí el cuerpo no está a salvo, contenido en la escritura, sino atravesado, contaminado, diagramando flujos de deseo. Creo que eso permite explicar mejor el retorno, la atención mutante pero insistente hacia las fugas sexo-genéricas irradiadas desde del mundo homosexual, desde las Yeguas del Apocalipsis hasta la CUDS, que exhibe la escritura de Richard en Abismos temporales. Y permite comprender, quizá de otro modo, su necesidad de advertir la tentación de la categoría mujer de caer en un refugio esencialista, para hacerla entrar en cambio, en el roce con vectores de deseo y desidentificación que impidan cerrarla. ${ }^{3}$

Por otra parte, el uso que Leppe hace de la injuria en la acción-instalación La Biblia de 1982, resulta para mí brillante e insuficientemente atendido. Aunque no volveré en detalle sobre ese discurso aquí, retener los anudamientos entre homosexualidad e injuria que el habla de Leppe ejecutaba, me permite hacer una acotación, o un énfasis sobre la cuestión de lo queer. La palabra queer en su uso anglosajón guarda un aspecto de posibilidad en su absorción de la injuria que, como se ha dicho ya en varias ocasiones, se pierde en su traducción al español y en los usos del término "disidencia sexual” (que acentúa en cambio, con la palabra disidencia, el gesto de una separación y de un antagonismo). Pero esto no nos impide recordar que la injuria es un antídoto frente a las lógicas normalizadoras e integradoras del orgullo, la injuria es el elemento parasitario que devuelve a lo queer su ambivalencia y su factor infeccioso, que lo alinea con lógicas antiheroicas, más disfuncionales y rezagadas. La injuria recuerda que lo queer designa modos de existencia que han sido envueltos en el estigma, el secreto, empujadas al disimulo, a la vergüenza. En efecto, autoras como Kosofsky Sedgwick plantean un brillante desplazamiento sobre la teoría de la performatividad del género al plantear que el nudo de la performatividad queer se juega en la vergüenza —en especial "en ese exilio biográfico que son las infancias queer" (1999: 202) - como un terreno de identificación y desidentificación que ofrece un espacio disponible para un trabajo de metamorfosis que, sin embargo, no se resuelve en una lógica de superación o depuración de la vergüenza. Estas formas de enredar y contaminar la relación entre vergüenza y orgullo, que sostienen las formas de perversidad, estigma, esterilidad, de las subjetividades queer, no sólo abren un campo extenso de reflexión que lleva a cuestionar todo "pensamiento recto" (para retomar una formulación de Nicolás Cuello). También encienden el punto de peligrosidad de las subjetividades maricas, camionas, lelas, bi y trans visibles, a la que sectores conservadores responden solicitando leyes y códigos contravencionales para la higienización del espacio

3 Una operación menos señalada o menos explicitada dice relación con los efectos desnaturalizantes que estos textos tienen sobre la construcción monolítica de la masculinidad, en tanto la de Richard, fue de las primeras escrituras críticas que, en el contexto chileno, mostró cómo las subjetividades homosexuales permiten comprender modos más complejos de encarnar y a la vez de padecer los efectos del patriarcado. 
público (como hemos visto en el contexto argentino de fines de 2018 con los proyectos de Nuevo Código Contravencional o Nuevos Códigos de Convivencia). Es desde las paradojas que logran sostener puntos de opacidad y negatividad, que la teoría queer cobra su mayor potencialidad.

Me interesa contrastar con estos matices, la sospecha sobre lo queer que plantea el libro, para recordar que esta teoría ha aportado un campo muy complejo de reflexiones que excede la cuestión de las identidades raras, excéntricas, investidas de cierto atractivoamenazante glamour. También quería destacar la alianza entre la escritura de Richard y una serie de prácticas y escrituras homosexuales, porque creo que efectivamente el lugar político y de enunciación de la homosexualidad, de colas, putos y maricas, es diferente al que plantean las subjetividades trans, que hablan de una trayectoria más difusa y subalterna en la historia de Chile. Y, para entrar entonces y para cerrar, en la cuestión, varias veces señalada en relación a la escritura de Richard, sobre los usos de lo trans, sobre las complejidades que plantean los usos de la fórmula "estéticas travestis".

Asidua a su gesto de desustancializar operaciones, lo trans como operación de simulación, aparece en Abismos temporales con énfasis positivos o negativos. Aparece con un valor crítico positivo para ilustrar y desnaturalizar la construcción social del género (en algunas prácticas de las Yeguas, por ejemplo, cuando Richard plantea que Lemebel y Casas hacen una parodia de la feminidad; cuando señala que "se disfrazan de travestis"), un uso que ya ha sido discutido (entre otrxs por Felipe Rivas). Pero también aparece al abordar el polémico sketch del diputado liberal de Evópoli, Felipe Katz, donde se lo ve vestido como una señora y lo escuchamos decir que, aunque no es mujer, defiende la equidad de género, pero omitiendo que se negó a apoyar la ley por la despenalización del aborto. El uso de la figura gramsciana del transformismo/travestismo político para señalizar el oportunismo político de una derecha que refina sus estrategias de intervención vuelve a asocia la travesti al simulacro, a la traición, a la farsa política, moral, de género. Difícilmente se utiliza el término transformismo/travestismo político en sentido inverso, como una potencialidad política.

En estos pasajes el travestismo aparece como pose o parodia, como una función de absorción y simbiosis que luego provoca un efecto de desrealización: lo masculino absorbiendo lo femenino para des-sustancializar lo femenino; el bloque político que absorbe el discurso de su adversario para neutralizarlo.
Sin embargo, el problema es cuando ciertos cuerpos solo parecen volverse inteligibles a través de figuras que Ixs desrealizan -como la parodia o el simulacro-. Sin embargo, reconocer ontologías trans, que no siempre pueden fijarse, no implica asimilarlas a un simulacro. Es posible decir que cuando se escucha la palabra género (por ejemplo, al decir género masculino o femenino), se escucha un mandato que dice: no hay que franquear la línea limítrofe. Las epistemologías trans introducen una distinción entre quienes atraviesan ese límite, esa frontera y quienes no lo hacen. En eso consiste la distinción entre cis y trans. El nudo de la cuestión deja de estar entonces en la desestabilización o ratificación sexo-genérica del binomio masculino/femenino (perturbación o adhesión a los ideales de género se dan variablemente, con mayor o menor éxito o fracaso tanto entre personas cis como entre personas trans). Lo que la distinción entre cis y trans busca visibilizar, en cambio, es que cruzar o no la frontera del género produce estatutos asimétricos de validez y realidad corporal. Están los cuerpos cis, que no transicionan y por tanto parecen tener una ontología más sólida, y los cuerpos trans que serían supuestamente artificiales o construidos, que siempre pueden ser codificados desde el disfraz, la máscara, la simulación, como si en las feminidades y masculinidades cis no actuaran tecnologías y artificios de género de manera permanente.

Me pregunto qué le puede hacer una categoría como la de cisexismo a nuestras formas de mirar y codificar la experiencia. Si estamos dispuestos a advertir el modo en que sostenemos nociones de naturaleza, consistencia, veracidad, unidad, soberanía, espontaneidad, incluso de radicalidad, que creíamos cuestionar.

En un texto reciente, el activista trans chileno Luc Gutiérrez, señalaba "el capitalismo es duro, pero es más duro para alguien que se desplaza, como saben bien migrantes y trans" (2018). La investigadora norteamericana Atalia Israeli-Nevo permite seguirle el hilo a esta afirmación, cuando vincula la borrosidad de marcadores temporales en la subjetividad migrante poscolonial con los efectos de la transfobia en las subjetividades trans, en términos de dos experiencias alentadas y forzadas a una posición fuera del tiempo. En sus palabras: "somos disociados de nuestros cuerpos, de nuestro entorno, [una] disociación que nos arroja a un futuro lejano en el que estaremos seguros después de haber pasado y haber encontrado un hogar corporal y social. Sin embargo, ese futuro es imaginario e inalcanzable, lo que nos lleva a estar fuera de tiempo" (2017). Una de las consecuencias de invocar lo trans como operación estética es que suele 
reiterar, suscribir de un modo desrealizante ese fuera del tiempo, cuando la perturbación de una norma y la transgresión de una identidad aparecen como condición de la existencia trans, en lugar de permanecer, de mantenerse en el vértigo del abismo para delinear otros modos de temporalidad y de realidad.

Si me detengo en este aspecto de los textos de Richard no es para realizar una sanción desde el resguardo aliviante de lo políticamente correcto. Sin duda, jugadas como las de Felipe Katz, que quieren hacer un guiño al feminismo desde un oportunismo transfóbico, hablan de una derecha mucho menos homogénea y lineal en su retórica y en sus formas de producir signos. Estamos presenciando la avanzada de grupos neoconservadores que combaten contra el difuso sintagma de la llamada "ideología de género" 4 en el plano legal y moral, con renovadas estéticas y retóricas. Una cruzada por re-naturalizar un binarismo basado en la anatomía corporal y la familia heterosexual conyugal. Al mismo tiempo, vemos una obsesión genitalista filtrarse afiladamente al interior de espacios feministas, remarcando fronteras y jerarquías para trazar cercos en torno a cuerpos no cisheterosexuales. ¿Cómo poder articular la preocupación ante lo que de pronto percibimos como una irritante zona de roce entre universos antagónicos, de una manera que no ceda ante fuerzas reaccionarias, si no que apueste por formas más subversivas del feminismo? Creo que resulta urgente una escritura dispuesta, una vez más, a abismar sus propias categorías, a manchar imprevisibles reclamos de pureza. Una escritura que se vuelva capaz de sostener (y a la vez de torcer) la presión simultánea de los diferentes y a la vez enmarañados campos de fuerza en juego. Algo a lo que la sagacidad de la propia escritura de Richard no deja de incitarnos, cada vez

\section{Q Bibliografía}

"Bracke, Sarah, and David Paternotte. 2018. "Desentrañando El Género." en ¡Habemus Género! La Iglesia Católica e Ideología de Género. Textos Seleccionados, 8-25. Rio de Janeiro, Brasil: Género y Política en América Latina.

"Gutiérrez, Luc. 2018. "Ser Trans O Ser Cis: La Falsedad de Los Nombres, La Verdad de Tenerlos." Http://Www.eldesconcierto.cl, May 23, 2018. http:// www.eldesconcierto.cl/2018/05/23/ser-trans-0ser-cis-la-falsedad-de-los-nombres-la-verdad-detenerlos/.

"Israeli-Nevo, Atalia. 2017. “Taking (My) Time: Temporality in Transition, Queer Delays and Being (in the) Present." Somatechnics 7.1: 34-49. https:// doi.org/10.3366.

»Kosofsky Sedgwick, Eve. 1999. "Performatividad Queer The Art of The Novel de Henry James." Nómadas (Col) 10: 198-214.

" Marchant, Patricio. 2000. "Sobre El Uso de Ciertas Palabras." en Escritura y Temblor, editado por Pablo Oyarzún and Willy Thayer. Santiago de Chile: Cuarto Propio.

" Mellado, Justo Pastor. 2009. “El Verbo Hecho Carne. De La Vanguardia Genital a La Homofobia Blanda En La Plástica Chilena." en En Todas Partes. Políticas de La Diversidad Sexual En El Arte., editedo por Juan Vicente Aliaga, 73-91. Santiago de Compostela: Centro Galego de Arte Contemporáneo.
4 La expresión “ideología de género" se utiliza para construir un enemigo homogéneo, pero se dirige a organizar acciones para bloquear procesos muy diferentes como la despenalización del aborto, la despatologización de las identidades trans o el llamado "matrimonio igualitario", algo que el texto de Richard también remarca. 